NBER WORKING PAPER SERIES

GAINS FROM TRADE IN

DIFFERENTIATED PRODUCTS:

JAPANESE COMPACT TRUCKS

\author{
Robert C. Feenstra
}

Working Paper No. 1978

NATIONAL BUREAU OF ECONOMIC RESEARCH

1050 Massachusetts Avenue

Cambridge, MA 02138

July 1986

Presented at the Columbia/NBER conference "Empirical Methods for International Trade," Apri1 3-4, 1986. The author thanks Panos Varangis for exceptional research assistance. The research reported here is part of the NBER's research program in International studies. Any opinions expressed are those of the author and not those of the National Bureau of Economic Research. 
Working Paper \#1978

July 1986

\title{
Gains From Trade in Differentiated Products: Japanese Compact Trucks
}

\begin{abstract}
We present a methodology for estimating the welfare gains from a product with new characteristics, and apply it to Japanese and American compact trucks. Our approach can be used on any products for which a hedonic regression can be estimated. For $1979-80$ we find average welfare gains of \$500-600 per Japanese truck. In later years the benefit to consumers is reduced by the tariff on imports and the introduction of American compact models. American compacts have consumer gains which are much less than the average for Japanese models, since for each American compact there is an import with very similar characteristics.
\end{abstract}

Robert C. Feenstra Department of Economics University of California Davis, CA 95616 


\section{Introduction}

Recent literature on monopolistic competition and trade has stressed the welfare gains available through importing new varieties of a differentiated product [see Helpman (1981), Krugman (1980), Lancaster (1980) and Helpman and Krugman (1985)]. In models which incorporate a description of goods in terms of characteristics, following Lancaster (1979), the welfare gains are especially large when the characteristics of the domestic and imported goods are quite different. In this paper we shall present a methodology for estimating the welfare gains from a product with new characteristics, and apply it to Japanese and American compact trucks. The application to Japanese compacts is of particular interest since prior to 1982 similiar American models did not exist.

Under free trade, the consumer gains we estimate for Japanese compact trucks are also social gains. Since August 1980, however, Japanese trucks have faced a tariff of $25 \%$, up from $4 \%$ previously. With this trade barrier we continue to measure consumer gains from the imports, and do not include the tariff revenue as would be required in a social calculation. For American compacts, available in 1982 and later, we also measure the consumer gains from having each model available. These benefits would need to be compared to the research and development costs of compact models to determine the net social gain or loss.

In section 2 we outline the theory behind our welfare measure. The model presented extends the analysis of Feenstra (1986) to discrete choice. In section 3 we discuss the recent history of the truck industry and present data on Japanese and American vehicles. Our empirical results are contained in section 4, while conclusions are given in section 5 .

We can briefly mention other approaches to estimating the gains from 
trade with differentiated products. Harris (1984) presents a general equilibrium model of Canadian-U.S. trade, and simulates the effects of reducing trade barriers. He obtains large estimates of the gains from free international trade. However, while product differentiation is present in some versions of the model, the main source of welfare gain is increasing returns to scale on the supply side. Bresnahan (1981) presents a model with monopolistic competition of the Lancaster type and applies it the U.S. automobile industry. Gains from new products could be estimated from this model, and also from the discrete choice literature pioneered by McFadden (1976). The main virtue of our own approach is its remarkable simplicity. This is achieved by focusing directly on the consumer gains from a new product, without estimating cross-sectional demand or modelling the supply side in depth.

2. Mode1 of Consumer Welfare

\section{A. Continuous Choice}

We shall suppose that the consumer purchases zero or one unit of a differentiated product, which we refer to as a truck, and any amount of a homogeneous good. Utility from consuming truck services is $U(q, \theta)$ where $q=$ $\left(q_{1}, \ldots, q_{n}\right)>0$ is a vector of physical characteristics (size, weight, horsepower, etc.), and $\theta=\left(\theta_{1}, \ldots, \theta_{n}\right)>0$ is a vector of taste parameters which differs across individuals. We shall adopt a specific functional form for utility,

$$
U(q, \theta)=\sum_{i=1}^{n} \theta_{i} q_{i}^{(\lambda)},
$$

$$
\text { where } \quad \begin{aligned}
q_{i}^{(\lambda)} & =\left(q_{i}^{\lambda}-1\right) / \lambda, \quad 0 \neq \lambda<1, \\
& =\ln q_{i}, \quad \text { if } \lambda=0 .
\end{aligned}
$$


(1) is a CES utility function defined over characteristics, where we permit negative values of $\lambda .{ }^{1}$ Reducing $\lambda$ corresponds to a more concave utility function.

Denoting the homogeneous good by $x>0$, the consumer chooses $q$ and $x$ to solve the problem,

$$
\begin{aligned}
& \max U(q, \theta)+x \\
& \text { subject to } p(q)+x=y,
\end{aligned}
$$

where the budget constraint is instead $\mathrm{x}=\mathrm{y}$ if no truck is purchased. In this problem $y$ denotes total income available to the consumer, $p(q)$ is the price of a truck depending on its characteristics, and the homogeneous good is used as numeraire. The additively seperable form of utility in (2) simplifies the welfare analysis, and implies that the optimal choice of truck characteristics $\mathrm{q}$ is independent of income.

Several points concerning the "hedonic" price function $p(q)$ should be noted. We suppose that this price function is exogenously presented to the consumer from the supply side of the market. Under perfect competition $p(q)$ would correspond to long-run marginal costs of firms, reflecting technology and factor prices. The competitive case has been throughly analysed by Rosen (1974). Under pure monopoly $p(q)$ would be chosen by the firm to maximize profits; this optimal control problem has been analysed by Mussa and Rosen (1978) and Krishna (1985). In that case $p(q)$ would depend on marginal costs and the distribution and utility function of consumers

We shall take $p(q)$ as exogenous, and in this section assume that a truck of any characteristics vector $q>0$ is available, corresponding to continuous choice for consumers. In section $B$ below we specialize our results to the 
case of discrete choice. We also assume in this section that domestically produced and imported trucks have the same hedonic price function, and do not even distinguish these sources of supply. In section $C$ below we consider a tariff on imported trucks, in which case the price functions will differ. Fina11y, throughout our analysis we shall use a specific functional form for $p(q)$, which corresponds to that used in our empirical application:

$$
p(q)=\exp \left(\alpha+\beta^{\prime} q\right)
$$

where $\alpha>0$ and $\beta=\left(\beta_{1}, \ldots, \beta_{n}\right)>0$ are parameters, and all vectors are treated as columns unless transposed using a prime.

If the consumer decides to purchase a truck, the first-order conditions for (1) are,

$$
\theta_{i} \tilde{q}_{i}^{\lambda-1}=\exp \left(\alpha+\beta^{-} \tilde{q}\right) \beta_{i}, \quad i=1, \ldots, n,
$$

where we use a tilde to denote the optimum. Thus, given any (unobserved) taste parameters $\theta$ we can use (4) to solve for the optimal truck choice $\tilde{q}$ for that consumer. But turning this logic around, for any truck $\tilde{q}$ we can use (4) to solve for the taste parameters $\theta$ of the consumer who would optimally choose that truck. We denote this relation by $\theta(q)=\left[\theta_{1}(q), \ldots, \theta_{n}(q)\right]$ where from (4),

$$
\theta_{i}(\tilde{q})=\exp \left(\alpha+\beta^{-} \tilde{q}\right) \beta_{i} \tilde{q}_{i}^{1-\lambda}
$$

This idea of solving for the taste parameters $\theta$ of a consumer whose optimal choice is $\tilde{q}$ will play a central role in evaluating the welfare gain from new 
products. For now, we simply observe that we can rewrite utility $U(q, \theta)$ as a function of actual consumption $q$ and a consumer's optimal choice $\tilde{q}$,

$$
U[q, \theta(\tilde{q})]=p(\tilde{q}) \sum_{i=1}^{n} \beta_{i} q_{i}^{(\lambda)} \tilde{q}_{i}^{1-\lambda},
$$

using (1), (3) and (4-).

Next, we should check whether the consumer desires to purchase a truck at a11. If $\lambda>0$ then when $q=0$ the consumer receives the disutility of $\theta / \lambda$, where $\bar{\theta}={ }_{i=1}^{n} \theta_{i}$. Then the consumer wishes to purchase the optimal choice $\tilde{q}$ if and only if,

$$
U(\tilde{q}, \theta)>p(\tilde{q})-\bar{\theta} / \lambda
$$

Multiplying (4) by $\tilde{q}_{i}$, subtracting $\theta_{i}$ and summing, we find that $U(\tilde{q}, \theta)=p(\tilde{q})$ $\beta-\tilde{q} / \lambda-\theta / \lambda$. It follows that (6) will hold if and only if,

$$
\beta^{-} \tilde{q}>\lambda
$$

If a consumer's optimal choice of characteristics $\tilde{q}$ is low, violating $\left(6^{-}\right)$, then the consumer prefers to not purchase the truck and receive disutility of $-\theta / \lambda$. Otherwise, when $\left(6^{\prime}\right)$ is satisfied the consumer obtains a higher level of surplus by purchasing the optimal truck choice. It can be shown that raising $\theta_{i}$ increases $\beta^{-} \tilde{q}$, so it is consumers with higher taste parameters $\theta$ who actually purchase a truck. ${ }^{2}$

Finally, if $\lambda \leqslant 0$ then $q=0$ leads to disutility of negative infinity, so in this case the optimal choice $\tilde{q}$ is always purchased. 
3. Discrete Choice

Suppose that some exogenous set $\Omega=\{\mathrm{q}\}$ of trucks is available to the consumer at the prices $p(q)$, given in (3). We include $O \varepsilon \Omega$ as the choice of not purchasing a truck. To maximize utility as in (2), each consumer will solve the problem,

$$
\max _{q \varepsilon \Omega}[U(q, \theta)-p(q)]
$$

Let $q^{*}$ denote the solution to (7), where this optimal choice depends on the taste parameters $\theta$ and the set $\Omega$.

Suppose now that a new truck model becomes available. To fix ideas, we can let $\Omega$ denote the set of American trucks and the new model be a Japanese compact truck. We are interested in evaluating the welfare gain due to the availability of the Japanese compact truck. Clearly, this gain depends on the distribution of consumers who actually purchase the new model. Let us focus on one individual of particular importance: the consumer for whom the newly available model would be the optimal choice in the continuous case where all models $q \geqslant 0$ exist. That is, let $\tilde{q}$ denote the new Japanese truck and consider the consumer with taste parameters $\theta(\tilde{q})$ given by $\left(4^{-}\right)$. The utility function for this consumer is given by (5). The gain from having the compact truck available is,

$$
\operatorname{Gain}=\{U[\tilde{q}, \theta(\tilde{q})]-p(\tilde{q})\}-\left\{U\left[q^{*}, \theta(\tilde{q})\right]-p\left(q^{*}\right)\right\} .
$$

Thus, the gain for this consumer is simply the difference between the surplus received from the best American choice $\mathrm{q}^{*}$ and the Japanese model $\tilde{\mathrm{q}}$. Next, we wish to evaluate the total consumer gain from having the 
Japanese truck available, and here we rely on an approximation. (8) gives us the welfare gain for the consumer who would optimally choose $\tilde{q}$ even if all models $q \geqslant 0$ existed. There will be other consumers who are just indifferent between some American model $\mathrm{q}^{*}$ and the Japanese model $\tilde{\mathrm{q}}$. These consumers receive a welfare gain of zero from the new model. We evaluate the total gain in welfare as the simple average between these two types of consumers, multiplied by the quantity of the Japanese model purchased:

$$
\text { Total consumer gain }=1 / 2 \times \text { Gain } x \text { Quantity . }
$$

There are two approximations implicit in (9). The first is that the individual consumer gain from having the compact truck available declines as a linear function of the quantity purchased, as we consider consumers whose optimal (continuous) choice lies further away from $\tilde{q}$. In other words, we are assuming a linear demand curve for the Japanese model. ${ }^{3}$ This approximation is analogous to that made in conventional measures of consumer surplus, and for that reason, we do not regard it as unusual.

However, a second approximation is that we are ignoring some consumers who receive an individual welfare gain greater than ( 8 ). To see this, we can evaluate how the extra utility received from the Japanese model changes with taste parameters:

$$
\begin{aligned}
\frac{\mathrm{d}}{\mathrm{d} \theta_{i}}\left[U(\tilde{q}, \theta)-U\left(q^{*}, \theta\right)\right] & =\tilde{q}_{i}^{(\lambda)}-\mathrm{q}_{i}^{*}(\lambda) \\
& <0 \text { if } \tilde{q}_{i}<q_{i}^{*}, \\
& >0 \text { if } q_{i}^{*}=0, \lambda>0 .
\end{aligned}
$$

Consider the case where the optimal choice of American truck $q^{*}$ is non-zero. 
Then since the Japanese compact truck has smaller characteristics than any standard American model, a consumer with taste parameters smaller than $\theta(\tilde{q})$ will receive a welfare gain from the Japanese truck which exceeds (8). If $\lambda>$ 0 , this logic applies until we reach a consumer who would not wish to purchase any American model, in which case the sign of (10) is reversed and lower values of $\theta$ reduce the welfare gain from the Japanese truck. 4

In our empirical analysis we shall not attempt to account for consumers with a welfare gain greater than (8). Accordingly, we regard the measure of total gain given by (9) as an underestimate of the actual welfare gain.

\section{Effects of a Tariff}

Consider the competitive case where the hedonic price function ( 3 ) is given by long-run marginal costs. An ad valorem tariff on Japanese imports corresponds to a rise in $\alpha$, increasing all prices by the same percentage. We then rewrite the hedonic price function as, 5

$$
p(q)=\left\{\begin{array}{l}
\exp \left(\alpha_{1}+\beta^{-} q\right) \text { for Japanese compact trucks, } \\
\exp \left(\alpha_{2}+\beta^{-} q\right) \text { for American standard trucks, }
\end{array}\right.
$$

with $\alpha_{1}>\alpha_{2}$ reflecting the tariff. The effects of a tariff on consumer choice in the continuous case have been analysed in Feenstra (1986). Here we simply wish to see how $\left(3^{-}\right)$affects our measure of welfare gain from a Japanese compact truck in the discrete case.

Using ( $\left.3^{-}\right)$the formulae for consumer gain in (8) and (9) are not affected. The empirical measure of gain is reduced since the price of any Japanese truck has increased. Indeed, for some values of $\lambda$ it is possible that the consumer gain in (8) is negative. This means that the surplus received from the Japanese model $\tilde{q}$, subject to the tariff, is less than the 
surplus available from an American model. It follows that the Japanese truck would not be purchased, which obviously contradicts the empirical evidence. We regard this situation as reflecting an incorrect choice of $\lambda$ in the utility function. For lower values of $\lambda$ the utility function becomes more concave, and the difference in characteristics between a Japanese compact and American truck can more than compensate for the tariff, leading to positive consumer gain in (8). This assertion is confirmed in our empirical analysis, where we use the occurence of negative values for (8) as a guide to choosing appropriate levels for $\lambda$.

\section{Japanese and American Trucks}

Through the $1960^{\circ} \mathrm{s}$ and $1970^{\circ} \mathrm{s}$ Japanese compact trucks were imported into the United State, while similar small domestic models were not produced. These trucks were imported by major Japanese producers as well as U.S. companies buying from subsidiaries or independent firms in Japan. Examples of the latter, known as "captive imports" are: General Motors, which imported the LUV pickup produced by Isuzu; Ford, which imported the Courier produced by Toyo Kogyo; and Chrysler, which imported the Arrow and Dodge D-50 compact trucks from Mitsubishi. This situation was altered in August 1980 by the imposition of a $25 \%$ tariff on Japanese truck imports, up from its former level of $4 \%$. The tariff increase led to the development of domestic compact trucks by the major U.S. producers, which were sold beginning in 1982.6 At this time all "captive imports" except the Dodge D-50 were discontinued.

The imposition of the $25 \%$ tariff on Japanese trucks has an unusual legislative history. In 1980, Ford and the UAW applied to the U.S. International Trade Commission (ITC) for import relief in both the the passenger car and the truck markets. Under Section 201 of the Trade Act of 
1974, a recommendation for relief can be given only if imports are the most important cause of injury to the domestic industry. The ITC determined that the recession in the U.S. was a greater cause of injury to the auto industry than rising imports, so import relief was not granted. Subsequent to this decision the "voluntary" export restraint in cars was negotiated with Japan (see Feenstra, 1984, 1985), while protection in trucks followed a different route.

At this time most Japanese trucks were imported as cab/chassis with some final assembly needed. In 1980 Congress asked the ITC to study the possible reclassification of Japanese imports from "parts of trucks" as then applied to "complete or unfinished trucks." The former carried a tariff rate of $4 \%$, whereas the latter had a duty of $25 \%$. That unusually high rate was a result of the "chicken war" between the United States and Europe in 1962-63, when Germany joined the EEC which raised its tariff on poultry imports. The U.S. retaliated by increasing the tariff on trucks (from Volkswagon) and other products. In 1980 the U.S. Customs Service announced that effective August 21 imported lightweight cab/chassis would be reclassified as complete trucks. This raised the tariff rate on nearly all Japanese trucks from 4 to $25 \%$.

In Table 1 we show the unit-values for new Japanese and American pickup trucks over 1979-84. These data summarize a sample collected from several different sources (listed in Tables 1, 2). Surprisingly, data reporting for trucks has been comprehensive only in recent years. The increase in the number of Japanese models included in our sample in 1983-84, and the increase in American models in 1984, reflects the greater availability of data. In earlier years the data included in our sample are only the base version of each particular truck model. For example, in 1983 and earlier years the base version of three standard pickups produced by GM (the C-10, C-20 and C-30) are 
included in our sample. In 1984 a total of eleven versions of these three models are included. Utility vehicles and vans were omitted from the sample, since it was found that these observations did not fit the same hedonic regression as trucks. 7

The prices in our sample are manufacturer's suggested retail. Taking the weighted average of the prices, using current year sales as weights, yields the unit-values in Table 1 . The effect of the $25 \%$ tariff on Japanese trucks is evident in the unit-value increase of $28.5 \%$ from 1980 to $1981 .^{8}$ The rise in the unit-value over 1982-83 should be interpreted with caution since, as mentioned above, in the former year only the base version of each model in included in our sample. The unit-values for American compact trucks over 1982-84, and for American standard trucks over the entire sample period, are also shown in Table 1.

In addition to manufacturer's suggested retail price, data were collected on various characteristics of truck models: length, weight, horsepower, fourwheel drive, type of transmission, and other specifications. In Table 2, this information is compared for Japanese and American models in 1982. In weight the average Japanese model is below the average American standard truck by $33 \%$, and in horsepower it is less by $23 \%$. We can also compare a large Japanese model (the Nissan 720 Kingcab) with a small American standard (the Dodge Ram D-50; similar models are produced by GM and Ford). In this case the Japanese compact is below the American standard in weight and slightly in length, but not in horsepower. Turning to American compact trucks, each of these are comparable in their price and characteristics to some Japanese model. In Table 2 we report the average values for American compacts, but do not give a high-low range: with only four observations, there is no model which has significantly more or less of all three characteristics than the 
average shown.

Data were also collected on the miles per gallon (MPG) of each truck model. It seems particularly important to include this specification in our study, since it may be an important source of consumer gain when purchasing a fuel-efficient Japanese model. To incorporate MPG into our analysis we follow the method of Atkinson and Halvorsen (1984), Ohta and Griliches (1983) and Daly and Mayor (1983). For each truck model we compute the "full price" as follows :

$$
\text { Full Price }=R+\sum_{t=0}^{T} G_{t} M_{t} / M P G(1+\rho)^{t} \text {, }
$$

where $R$ is the manufacturer's suggested retail price, $G_{t}$ is the real price of gasoline in year $t, M_{t}$ is the number of miles driven in year $t$, $\rho$ is the discount rate, and $T$ is the lifetime of the truck. Thus, the full price includes the retail price of the truck and the present discounted value of gasoline costs. 9

Values for the discounted gasoline costs in 1982 are shown in Table 2 . These costs range between one-half and three-quarters of the retail price of a truck. We have chosen a discount rate of $7 \%$, though it was found that the estimates of the hedonic regressions reported below (and the implied welfare calculations) were not sensitive to this choice. In the hedonic regressions we use the "full price" as the dependent variable.

\section{Empirical Results}

\section{A. Hedonic Regressions}

We estimate the hedonic price function (3) to obtain the coefficients $B$ needed in our welfare calculations. We shall use the estimating form, 


$$
\ln p_{t, k}=\alpha_{t}+\beta^{-} q_{t, k}+\varepsilon_{t, k}
$$

where $t$ denotes years, $k$ denotes models and $p_{t, k}$ is the "full price" of a truck as in (11). We also allow $\alpha_{t}$ to differ between compact and standard models. The use of hedonic regressions was proposed by Griliches (1971), while recent applications are in Atkinson and Halvorsen (1984) and Ohta and Griliches (1983). Feenstra (1984, 1985, 1986) uses this technique to measure quality upgrading in Japanese cars Imported to the U.S. under the trade restraint.

In the first column of Table 3 we report the hedonic regression for Japanese models, while that for American models is given in the second and third columns. Each estimated coefficient can be given a useful interpretation: the addition of one foot in length, for example, raises price by an estimated $1.4 \%$ for Japanese and $2.3 \%$ for American trucks, where the latter is significant. Weight and horsepower are each highly significant in at least one of the regressions. The dummy variable for transmission takes the value of unity if the truck has a five-speed or automatic transmission and zero otherwise, and similarly for four-wheel drive. 10

In the lower portion of Table 3 we show the coefficients of dumn variables for each year, relative to 1979. These coefficients measure the rise in nominal prices after correcting for changes in model characteristics: the "quality-adjusted" price rise. From 1979 to 1981 the quality-adjusted price rise is $23 \%$ for Japanese models, and this coefficient is nearly the same in the following years. Thus, after correcting for quality change the prices of Japanese trucks are roughly constant over 1981-84. This pattern is also seen for the quality-adjusted price rise in American compact trucks, which is 
29\% from 1979 to 1982 and similar in following years (second column, Table 3). In contrast, for American standard trucks we see a steady rise in quality-adjusted prices over 1981-84 (third column).

If the Japanese and American regressions are not significantly different, then our data can be combined to improve the efficiency of the estimates. We test this hypothesis by running the pooled regression shown in the fourth and fifth columns of Table 3. In this case the coefficients $\beta$ are equal for compact and standard trucks. We also impose equal value of $\alpha_{t}$ for Japanese and American compact trucks. For American standard trucks, the value of $\alpha_{t}$ differs from compact trucks for 1981, 1982 and 1984. Overall, we find that the pooled regression is not statistically different from the seperate regressions shown in Table 3. Using the sum of squared residuals (SSR) shown, the F-statistic to test the various restrictions in the pooled regression is $[(0.333-0.299) / 11] /(0.299 / 151)=1.56$ which compares with $F_{0.95}(11,151)=$ 1.85. Thus, we can accept these restrictions.

We also checked whether the quality coefficients of the pooled regression in Table 3 were stable over time, by estimating the regression seperately for each year. The resulting SSR was 0.282 with a total of 42 coefficients. The F-statistic to test whether the quality coefficients are equal over time is $[(0.333-0.282) / 28] /(0.282 / 134)=0.866$ which compares with $F_{0.95}(28,134)=$ 1.55. Thus, we accept the hypothesis of stable quality coefficients.

We shall use the coefficients of the pooled regression in Table 3 for the welfare calculations that follow. We see that each of length, weight and horsepower are highly significant. Since Japanese and American compact models have the same values of $\alpha_{t}$, these trucks are comparable in their prices. American standard trucks have a lower value of $\alpha_{t}$, or quality-adjusted price, for the two years 1980-81 following the imposition of the $25 \%$ tariff on 
imported models. However, in 1984 we find that quality-adjusted prices for American standard trucks have risen above those of compact models, with a higher value of $\alpha_{t}$.

\section{B. Welfare Calculation}

Before computing the welfare gain from having compact trucks available, we need to carefully explain how our theory of section 2 is applied to the data. Note, that in section 2 each of the characteristics $q_{i}$ were measured as continuous variables. The theory developed there cannot be used for discrete variables such as transmission or four-wheel drive. Accordingly we shall treat each truck model as not including either of these characteristics. To achieve this, if a model does come equipped with a five-speed or automatic transmission then we divide its price by $\exp (0.016)$ (using the coefficient from Table 3, pooled regression), and we divide its price by $\exp (0.19)$ if equipped with four-wheel drive.

We must also deal with the residuals in our estimated hedonic regression, that is, the difference between actual and predicted prices. There are two approaches which can be taken. First, we could assume that the residual for each model reflects unmeasured characteristics of that truck. An example of this would be power steering, for which data was not available on American models.1l In this case a low price (negative residual) would indicate some undesirable specification of the truck, and would not lead to any rise in consumer surplus. At the other extreme, we could assume that any difference between actual and predicted prices is unrelated to model specifications, so a negative residual would lead to a rise in consumer surplus by exactly that dollar amount.

It turns out that the latter assumption is inconsistent with our data. 
We find one model in particular - the C-10 standard pickup produced by General Motors - which has negative residuals in the hedonic regression ranging from $-\$ 300$ to $-\$ 1,000$ dollars in various years. If this represents a source of gain to consumers buying the truck, then it may be impossible to identify a consumer who would wish to purchase a Japanese compact (which had much smaller residuals). Put differently, when the negative residual from the $C-10$ is added to (8), the resulting consumer gain from having the compact truck available would be negative. Accordingly, in our calculations below we rely on the former assumption, that each residual reflects unmeasured characteristics. This means that we use the predicted price from the hedonic regression as reflecting what people pay for the three characteristics we have identified (length, weight, horsepower). Thus, the predicted price corresponds to $p(q)$ in $(3)$ or $\left(3^{-}\right)$.

We can now briefly review how our welfare calculation is performed. Choose some value for $\lambda$ in the utility function (1), and let $\widetilde{q}$ denote the characteristics of a Japanese model. Then we use $\left(4^{-}\right)$to solve for the taste parameters of a consumer who would optimally choose this model. Let $\Omega$ denote the set of American models (compact or standard). For this consumer we determine the best American choice $q^{*}$ in (7), and then compute the consumer gain as in (8), (9). We repeat this calculation for each Japanese model $\tilde{q}$ in each year. In addition, we do the same calculation for each American compact model over 1982-1984. In that case $\tilde{q}$ denotes an American compact, $\Omega$ the set of Japanese models, and $q^{*}$ the best Japanese choice.

In Table 4 we show the results of our welfare calculation for $\lambda=-8,-10$ and -15. The consumer gains shown are expressed in dollars per truck purchased. We first report a weighted average of the gains for individual Japanese and American models, using current year sales as weights. These 
figures could be multiplied by the quantities in Table 1 to obtain the total consumer gain (9). We also report the range of welfare gains obtained over individual Japanese and American models.

Considering first the Japanese models, recall that these had a value of $\alpha_{t}$ in the hedonic regression which exceeded American standard trucks for 1981 and 1982. That is, due to the tariff the import prices exceeded those of domestic standard trucks after correcting for quality differences. From our discussion in section $2 \mathrm{C}$, it is then possible that the welfare gains due to a Japanese model may be negative for some values of $\lambda$. This means that the consumer benefits due to having a truck with smaller characteristics available are less than the tariff. Under these circumstances, we argued that $\lambda$ should be reduced to allow for greater concavity of the utility function.

With $\lambda \geqslant 0$ we found that all nine Japanese models had negative gain in 1981. This result continues for some negative values of $\lambda$ : for example, at $\lambda$ $=-5$ six Japanese models have negative gain in 1981. The first value at which most Japanese models have positive welfare gain is $\lambda=-8$, and these results are shown in the first rows of Table 4.12 We regard these as minimum estimates of the consumer gains (or actually underestimates, as argued in section 2B). In 1979 and 1980 the average gains are $\$ 530$ and $\$ 486$ per truck, respectively, which are $10 \%$ or more of the average retail price. In 1981 the consumer gain drops to $\$ 87$ due to the tariff on Japanese compacts. After 1981 there are two opposing effects on the measure of gain: the price differential between Japanese trucks and American standard models is reduced (and reversed by 1984), while at the same time American compact trucks become available. The first effect raises the welfare gain due to Japanese pickups while the second effect lowers it. For 1982-84 we see that the consumer gain remains substantially less than its value before 1981 , varying around $\$ 100$ per truck. 
In the next rows of Table 4 the results for $\lambda=-10$ and -15 are shown. Considering $\lambda=-15$, the average consumer gains for Japanese trucks in 1979 and 1980 are $\$ 628$ and $\$ 582$, respectively. These figures substantially exceed $10 \%$ of the retail price (unit-value) in Table 1 . Moreover, the consumer who would optimally choose each Japanese model under continuous choice receives a gain which is twice as high (compare (8) and (9)), or over $20 \%$ of the retail price. In later years the consumer gains fall due to the tariff on Japanese trucks and the introduction of American compact models, varying around $\$ 200$ per truck over 1981-84.

Turning to American compact models, we obtain estimates of consumer gains due to these models which are surprisingly low. For example, with $\lambda=-15$ the gain is $\$ 23-32$ per truck over 1982-84. The reason is that for each American compact in our sample there is a Japanese truck with very similiar characteristics. As a result, the gains to consumers from having either the American or corresponding Japanese truck available, given that the other model already exists, are small. From the ranges reported in Table 4 is is seen that the low gains on American trucks also occur for some Japanese models. However, in each year there are other Japanese models which are not that similar to an American model. As a result, the average consumer gains for Japanese trucks over 1982-84 are much greater than for American compacts.

\section{Conclusions}

In this paper we have presented a methodology for estimating the welfare gains from a product with new characteristics, and applied it to Japanese and American compact trucks. Our approach can be used on any products for which a hedonic regression can be estimated. The coefficients of this regression, together with the parameter $\lambda$ indicating concavity of the utility function, 
are enough information to perform the welfare calculation. The application to Japanese compact trucks is of particular interst since prior to 1982 similar American models did not exist.

For 1979-80 we found average welfare gains of $\$ 500-600$ per Japanese truck. Multiplying these figures by the quantity of trucks purchased each year gives the total consumer gains. In later years the benefit to consumers is reduced by the tariff on imports and the introduction of American compact models. For 1982-84 we found welfare gains of about $\$ 100-200$ per Japanese truck, though the range was considerably wider for individual models. In evaluating consumer benefits we have not included tariff revenue on Japanese Imports, as would be necessary in a social calculation.

American compacts had consumer gains which were much less than the average for Japanese models, since for each American compact there was an import with very similar characteristics. For American trucks the consumer gains would need to be compared to research and development costs of compact mopdels to determine the net social gain or loss. If the average gains of \$15-30 we found per American compact are less the R\&D costs, then the additional diversity introduced by American models is not socially desirable. However, we should note that the present study has not included vans and utility vehicles. There are many more compact vehicles of this type introduced by American than by Japanese producers. Accordingly, some American compact vans or utility vehicles would not have similar imported versions, and we would expect larger consumer gains due to the availability of these products. 


\section{References}

Atkinson, Scott E. and Robert Halvorsen (1984) "A New Hedonic Technique for Estimating Attribute Demand: An Application to the Demand for Automobile Fue1 Efficiency," Review of Economics and Statistics, 417-426.

Bresnahan, Timothy F. (1981) "Departures from Marginal-Cost Pricing in the American Automobile Industry: Estimates for 1977-1978," Journal of Econometrics 17, 201-27.

Daly, George G. and Thomas H. Mayor (1983) "Reason and Rationality during Energy Crises," Journal of Political Economy 91(1), February, 168-181. Feenstra, Robert (1984) "Voluntary Export Restraint in U.S. Autos, 1980-81: Quality, Employment and Welfare Effects," in Robert E. Baldwin and Anne 0. Krueger, eds., The Structure and Evolution of Recent U.S. Trade Policy. NBER. Chicago: University of Chicago Press.

Feenstra, Robert C. (1985) "Automobile Prices and Protection: The U.S.-Japan Trade Restraint," Journal of Policy Modelling, Spring.

Feenstra, Robert C. (1986) "Quality Change under Trade Restraints: Theory and Evidence from Japanese Autos," University of California, Davis, May. Griliches, Zvi (1971) "Hedonic Price Indexes for Automobiles: An Econometric Analysis of Quality Change," in Zvi Griliches, ed. Price Indexes and Quality Change. Cambridge: Harvard University Press.

Harris, Richard (1984) "Applied General Equilibrium Analysis of Small Open Economies with Scale Economies and Imperfect Competition," American Economics Review 74(5), December, 1016-1032.

Helpman, Elhanan (1981) "International Trade in the Presence of Product Differentiation, Economics of Scale and Monopolistic Competition: A Chamberlin-Heckscher-Ohlin Approach," Journal of International Economics 11, August, 305-40. 
Helpman, Elhanan and Paul R. Krugman (1985) Market Structure and Foreign Trade. MIT Press: Cambridge, MA.

Krishna, Kala (1985) "Protection and the Product Line: Monopoly and Product Quality," NBER Working Paper no. 1537, January.

Krugman, Paul R. (1980) "Scale Economies, Product Differentiation, and the Pattern of Trade," American Economic Review 70, December, 950-59. Lancaster, Kelvin J. (1979) Variety, Equity, and Efficiency. Columbia University Press: New York.

Lancaster, Kelvin J. (1980) "Intra-Industry Trade under Perfect Monopolistic Competition," Journal of International Economics 10, May, 151-75.

McFadden, Daniel (1976) "Quantal Choice Analysis: A Survey," Annals of Economic and Social Measurement 5, 363-390.

Ohta, Makoto and Zvi Griliches (1983) "Automobile Prices and Quality: Did the Gasoline Price Increase Change Consumer Tastes in the U.S.?" NBER working paper no. 1211 , October. 
Table 1: Sample of Japanese and American Trucks

$\begin{array}{llllll}1979 & 1980 & 1981 & 1982 & 1983 & 1984\end{array}$

Japanese

No. of models

8

Unit-Value ( $\$$ )

Quantity $(1,000)$

4,741

8

9

9

16

16

464

4,907

6,304

6,389

7,097

7,229

Quantity (1, 000)

479

427

403

440

649

American Compact

$\begin{array}{lcccccc}\text { No. of models } & 0 & 0 & 0 & 4 & 5 & 6 \\ \text { Unit-Value }(\$) & - & - & - & 6,279 & 6,338 & 6,485 \\ \text { Quantity }(1,000) & 0 & 0 & 0 & 282 & 410 & 466\end{array}$

American Standard

\begin{tabular}{lcccccc}
\hline No. of models & 16 & 13 & 13 & 13 & 13 & 27 \\
Unit-Value $(\$)$ & 5,601 & 6,059 & 6,646 & 7,572 & 7,709 & 8,640 \\
Quantity $(1,000)$ & 1,971 & 1,287 & 1,112 & 1,000 & 997 & 1,304 \\
\hline
\end{tabular}

\section{Sources:}

Prices for Japanese models were obtained from Automotive News, Market Data Book, 1979-84 years. Prices for American models were obtained from the National Automobile Dealers Association (NADA), Official Used Car Guide, Eastern Edition, July 1985. All prices are manufacturer's suggested retail. Quantities were obtained from Ward's Automotive Yearbook, 1979-84, reported by company. These were divided equally over the models of each company. 
Table 2: Japanese and American Trucks, 1982

$\begin{array}{ccccc}\text { Price } & \text { Length } & \text { Weight } & \text { Horsepower } & \text { Gasoline } \\ (\$) & \text { (feet) } & \text { (lbs.) } & \text { Cost (\$) }\end{array}$

$\begin{array}{lccccr}\begin{array}{l}\text { Japanese } \\ \text { Weighted Average }\end{array} & 6,389 & 14.6 & 2,571 & 92 & 3,633 \\ \text { Low (Isuzu Pickup) } & 6,129 & 14.5 & 2,374 & 78 & 3,273 \\ \text { High (Nissan 720 King) } & 7,229 & 15.6 & 2,999 & 98 & 3,819 \\ \text { Anuerican Compact } & & & & & \\ \text { Weighted Average } & 6,279 & 14.7 & 2,422 & 79 & 3,351 \\ \text { American Standard } & & & & & \\ \text { Weighted Average } & 7,572 & 16.8 & 3,847 & 120 & 5,158 \\ \text { Low (Dodge D-100) } & 6,721 & 16.1 & 3,405 & 90 & 4,365\end{array}$

\section{Sources :}

Characteristics for Japanese models were obtained from Automotive News, Market Data Book, 1979-84 years. Characteristics for American models were obtained from Ward's Automotive Yearbook, 1979-84. Miles per gallon data, used in constructing gasoline costs, are from the Environmental Protection Agency as reported in Automotive News and Ward's. Weighted averages use current year sales as weights. 
Table 3: Hedonic Regressions, Dependent Variable - Full Price

\begin{tabular}{|c|c|c|c|c|c|}
\hline \multirow[t]{2}{*}{ Sample } & \multirow[t]{2}{*}{ Japanese } & \multicolumn{2}{|c|}{ American } & \multicolumn{2}{|c|}{ All Trucks } \\
\hline & & Compact & Standard & Compact & Standard \\
\hline Obs. & 66 & 15 & 95 & 81 & 95 \\
\hline $\mathrm{R}^{2}$ & 0.947 & \multicolumn{2}{|c|}{0.944} & \multicolumn{2}{|c|}{0.955} \\
\hline SSR & 0.105 & \multicolumn{2}{|c|}{0.194} & \multicolumn{2}{|c|}{0.333} \\
\hline Constant & $\begin{array}{r}8.25 * \\
(0.17)\end{array}$ & \multicolumn{2}{|c|}{$\begin{array}{c}8.08 * \\
(0.080)\end{array}$} & \multicolumn{2}{|c|}{$\begin{array}{c}8.13^{*} \\
(0.062)\end{array}$} \\
\hline Length (feet) & $\begin{array}{c}0.014 \\
(0.012)\end{array}$ & \multicolumn{2}{|c|}{$\begin{array}{c}0.023 * \\
(0.0065)\end{array}$} & \multicolumn{2}{|c|}{$\begin{array}{c}0.021 * \\
(0.0055)\end{array}$} \\
\hline Weight (tons) & $\begin{array}{c}0.18 \\
(0.11)\end{array}$ & \multicolumn{2}{|c|}{$\begin{array}{c}0.28 * \\
(0.039)\end{array}$} & \multicolumn{2}{|c|}{$\begin{array}{l}0.27 \\
(0.025)\end{array}$} \\
\hline Horsepower $(100)$ & $\begin{array}{c}0.30 * \\
(0.063)\end{array}$ & \multicolumn{2}{|c|}{$\begin{array}{c}0.17 * \\
(0.027)\end{array}$} & \multicolumn{2}{|c|}{$\begin{array}{c}0.18^{*} \\
(0.024)\end{array}$} \\
\hline Transmission & $\begin{array}{r}0.037 * \\
(0.017)\end{array}$ & \multicolumn{2}{|c|}{$\begin{array}{c}0.010 \\
(0.013)\end{array}$} & \multicolumn{2}{|c|}{$\begin{array}{l}0.016 \\
(0.0088)\end{array}$} \\
\hline Four-wheel Drive & $\begin{array}{c}0.23 * \\
(0.024)\end{array}$ & \multicolumn{2}{|c|}{$\begin{array}{c}0.18 * \\
(0.013)\end{array}$} & \multicolumn{2}{|c|}{$\begin{array}{c}0.19 \\
(0.011)\end{array}$} \\
\hline Year 1980 & $\begin{array}{r}0.069 * \\
(0.029)\end{array}$ & - & $\begin{array}{c}0.079 * \\
(0.017)\end{array}$ & $\begin{array}{r}0.077 * \\
(0.014)\end{array}$ & $\begin{array}{r}0.077 * \\
(0.014)\end{array}$ \\
\hline Year 1981 & $\begin{array}{c}0.23 * \\
(0.021)\end{array}$ & - & $\begin{array}{c}0.16 * \\
(0.017)\end{array}$ & $\begin{array}{c}0.24^{*} \\
(0.019)\end{array}$ & $\begin{array}{c}0.15^{\star} \\
(0.016)\end{array}$ \\
\hline Year 1982 & $\begin{array}{c}0.23 * \\
(0.022)\end{array}$ & $\begin{array}{c}0.29 * \\
(0.033)\end{array}$ & $\begin{array}{c}0.23^{*} \\
(0.017)\end{array}$ & $\begin{array}{c}0.26 * \\
(0.017)\end{array}$ & $\begin{array}{c}0.22 * \\
(0.016)\end{array}$ \\
\hline Year 1983 & $\begin{array}{c}0.21 * \\
(0.022)\end{array}$ & $\begin{array}{c}0.27 * \\
(0.032)\end{array}$ & $\begin{array}{c}0.26 * \\
(0.017)\end{array}$ & $\begin{array}{c}0.25 * \\
(0.013)\end{array}$ & $\begin{array}{c}0.25 * \\
(0.013)\end{array}$ \\
\hline Year 1984 & $\begin{array}{c}0.22 * \\
(0.022)\end{array}$ & $\begin{array}{c}0.30 * \\
(0.029)\end{array}$ & $\begin{array}{c}0.32 \\
(0.015)\end{array}$ & $\begin{array}{c}0.26 * \\
(0.015)\end{array}$ & $\begin{array}{c}0.32 * \\
(0.014)\end{array}$ \\
\hline
\end{tabular}

*Significant at $95 \%$ level. Standard errors are in parentheses. 
Table 4: Consumer Gain from Compact Trucks (Dollars)

\begin{tabular}{|c|c|c|c|c|c|c|}
\hline & 1979 & 1980 & 1981 & 1982 & 1983 & 1984 \\
\hline \multicolumn{7}{|l|}{$\lambda=-8$} \\
\hline Japanese Average & 530 & 486 & 87 & 79 & 139 & 103 \\
\hline Range & $454-598$ & $376-538$ & $0-169$ & $0-145$ & $10-345$ & $9-470$ \\
\hline American Average & - & - & - & 17 & 13 & 17 \\
\hline Range & - & - & - & $9-51$ & $8-28$ & $11-41$ \\
\hline \multicolumn{7}{|l|}{$\lambda=-10$} \\
\hline Japanese Average & 567 & 522 & 126 & 110 & 173 & 124 \\
\hline Range & $479-638$ & $404-578$ & $0-214$ & $15-198$ & $13-397$ & $10-489$ \\
\hline American Average & - & - & - & 21 & 16 & 21 \\
\hline Range & - & - & - & $10-64$ & $10-33$ & $13-50$ \\
\hline \multicolumn{7}{|l|}{$\lambda=-15$} \\
\hline Japanese Average & 628 & 582 & 193 & 222 & 272 & 189 \\
\hline Range & $537-701$ & $450-645$ & $0-286$ & $22-397$ & $19-521$ & $14-640$ \\
\hline American Average & - & - & - & 32 & 23 & 32 \\
\hline Range & - & - & - & $14-99$ & $14-47$ & $19-70$ \\
\hline
\end{tabular}

